\title{
Research on the Construction of College Students' Apartment Culture
}

\author{
Jingang Bai \\ Office of Student Affairs of Chifeng University \\ Inner Mongolia, China
}

\begin{abstract}
Apartment culture is an important part of school culture. A positive, healthy, and optimistic apartment culture can help college students form a correct world view, outlook on life and values and a development view. However, there are still some problems concerning the ideas on the construction of the apartment culture, including that people are indifferent towards the construction of the apartment culture. New conceptions which can meet the demands of the new age are actually scarce. The system of the construction of apartment culture is imperfect and the ability of constructing the apartment culture is weak. Therefore, universities are supposed to attach very importance to the construction of apartment culture, free their minds, excavate and probe into the apartment culture, keep pace with the times and make the apartment culture into the eye-catching brand culture, and they should take the educational function of the apartment culture as the central theme, and make the apartment culture close to the students' thoughts and practical life. Therefore, the universities are expected to facilitate the development of the construction of the apartment culture in a balanced way.
\end{abstract}

\section{Keywords-Student Apartment; Cultural Construction}

\section{INTRODUCTION}

With the rapid development of higher education and the acceleration of logistic socialization, student apartment has become the important position for political education and cultural education. According to the calculation, the college students spend almost half of college life in their apartments. Student apartment is the important place where the students do the ordinary routines and live the ordinary life. Therefore, apartment culture will exert a profound influence on their growth. Meanwhile, apartment culture is also the significant part of higher school culture. So, building the civilized and harmonious apartment culture will have a great influence on implementing the quality education and fostering the excellent college students. Based on experience accumulated for many years, I will briefly talk the connotation, significance and the approach of implementation of the construction of apartment culture.

\section{THE NeCESSITY OF CONSTRUCTING THE COLLEGE STUDENTS' APARTMENT CULTURE}

Owing to its peculiar connotation and characteristic, the construction of college student apartment culture has a great influence on the education and development of college students. It has become a new important position facilitating the healthy development of the students after the first class[1]. It is closely related to the form of campus culture and even to the growth and cultivation of the college students.

\section{A. The Connotation of the College Student Apartment Culture}

Apartment culture takes the apartment community as the carrier, the students as the main body, the university-company association as the mechanism, the environmental construction as the foundation, the institutional construction as the assurance, the accumulation and innovation as the principle, the campus harmony as the objective, the socialist cored value as its content, the political and thought education into the apartment as the approach, the cultural activities as the platform, the apartment spirit as the symbol, and the achievements of the students as the core[2]. The ideological, intellectual and interesting apartment culture can be produced in an unconscious way, which condense the dense campus spirit and atmosphere of humanism and embody the vigorous and passionate quality of youthful students and enlighten the students to work hard and bravely bear their responsibilities and cultivate noble sentiment and moral qualities of youthful students and enrich the students' cultural life and spiritual world and thus facilitate the form of school spirit, teaching spirit and learning spirit.

\section{B. The Characteristics of College Students Apartment Culture}

Every culture has its own characteristics and college student apartment culture is no exception. It has many characteristics including educational humanism and continuity, regional stability and openness, automatic and massive engagement, the selectivity and integrity for activities, equality and democracy for communication, popularity and secularity of performance, multi-layer and complexity of cultural structure, peculiarity and succession of its brand and idealism and reality of its value objective, which all have their own functions.[3-4] and exert a great influence on the development of the students unconsciously. 


\section{The Significance of the Construction of the College Student Apartment Culture}

With the continuous penetration of logistic socialization, the educational function of the apartment culture is gradually raising people's attention. Apartment culture is the important part of campus culture, which plays the role making the students form the belief that society is first, family is second and class is third. Positive, healthy, civilized and optimistic apartment culture is the important carrier for cultivating talents and also the forward position for students' political and ideological education and also the instructive complementation for classroom education and the extension of family education and the step of practice before entering the society and the adhesion of condensing the friendship among the students and is also conducive to the form of world views, outlooks of life and values and the development views of the college students.[5] Therefore, in terms of realizing the free and inclusive development of the students and cultivating the qualified builder and reliable successor of socialist cause with Chinese characteristics, strengthening the construction of college student apartment culture has its significance.

\section{The PROBlems IN THE CONSTRUCTION OF THE COLlege STUdent APARTMENT CUlture}

The construction of college student apartment culture is the important content of campus culture and also the carrier for cultivating the talents for universities. However, there are still problems in terms of the belief on the construction of the apartment culture and there isn't sufficient new conceptions applying to the requirements of the new era.

\section{A. Indifference towards the Conception of the Construction of the College Student Apartment Culture}

First, the ideological recognition towards the construction of the college student apartment culture is insufficient.

Some universities have no sufficient and correct understanding for the significance and the educational function of the construction of apartment culture. They have not yet realized that the college apartment culture is the significant part of condensing campus spirit and only take the apartment culture as the low-level activities. As the main body of the construction of the apartment culture, teachers, ideological and political workers and school managers have not yet engaged into it thus causing the conformism and developmental lag-behind even resulting in that vulgar culture takes the space of the apartment culture owing to the influence of the nonmainstream culture.

Second, the cultural individuality is less prominent.

In the process of constructing the apartment culture, the campus spirit cannot penetrate into the apartment community very well. Apartment environment culture is not good and the establishment of connotation is quite superficial. Exclusive higher school student apartment culture spirit has not yet formed. Thus many fake culture appear, cultural individuality is inadequate and even all the culture are of great sameness.
Third, subjectivity isn't exhibited thoroughly.

The college students are in their own prime time in their life, in which they have outstanding individualities, and are malleable, random, impetuous, impulsive, and self-centered and they lack reasonability and legal consciousness. We can see that the college students are dependent, utilitarian, craven, fickle and lacking in their own judgement, comparative, instable and less than independent. Their competence in selfeducation, self-management, self-service and selfdevelopment are comparatively weak, which causes that their subjectivity in the construction of the college student apartment culture is insufficient.

\section{B. The Lack of the Institutional Construction of Apartment Culture}

First, the root of institutional insufficiency lies in the current institutional system. Since the social reform of logistic socialization in higher schools, apartment management has changed institutionally, that is, apartment group is in charge of student apartment. Owing that school student management department cannot supervise the apartment directly, they each cannot integrate efficiently.

Second, the utilitarian value will obstruct the system improvement. Apartment group has the property of company, that is, they pursue the optimization of their benefit[6]. The objective of school is education, which means realizing the free and comprehensive development of the college students. Owing to the different objectives, the institution cannot connect efficiently. Third, conformism is the major reason for the institutional insufficiency. In the process of the construction of apartment culture, top-level design, reasonable programming, long-term development and theoretical research are insufficient. Only depending on experience and lacking vision and insight originality leads to the construction of institutional culture backward.

\section{The Weakness of the Team of Construction of Apartment Culture}

The most of the administrative staff of apartment are temporary workers with older age, lower educational background, bad service ability, big generation gap and incorrect location. They don't understand the characteristics of the college students and law of development of students and their work orientation are merely cleaning and guarding. They are not qualified for educating and managing the college students and instructing the college students to carry out the construction of apartment culture. To some degree, their work cannot be recognized by the students. 


\section{THE APPROACH TO THE CONSTRUCTION OF COLLEGE STUDENTS' APARTMENT CULTURE}

The construction of the college student apartment culture is a fantastic landscape in the construction of campus culture in higher schools, which can not only enrich the content of campus culture but accelerate the transformation and extension of campus culture spirit. Therefore, higher schools should attach very importance to the construction of college student apartment culture, free their minds, excavate and probe into the apartment culture, keep pace with the times, make the apartment culture into the eye-catching brand culture take the educational function of the apartment culture as the central theme, and have the apartment culture close to the students' thoughts and practical life. Therefore, the universities are expected to facilitate the development of the construction of the apartment culture in a balanced way.

\section{A. Setting up Scientific Organizations and Institutes and Smooth Mechanism and System.}

First, the department concerned needs to implement the first-level management system and the strip operation, send service directly to the students, improve the service quality and reinforce the educational efficiency, and then build up the uniform school management system, that is, the relative department should work out the general planning and development of apartment management and the construction of apartment culture charged concretely by logistic apartment group, which is led by one committee member leader. Under the logistic apartment group, the school should set up the Group Office responsible for the talent recruitment center for logistic group, the outreach center, the apartment park green and the cleaning center and the apartment group water and heating, the infrastructure center. Second, they should set up general party branch and youth league general branch in each apartment building and also party branch and youth league branch in each floor, and also organize party group and youth league group among several adjacent dormitories. In this way, the pyramid structure can be formed, providing the strong organizing guarantee.

\section{B. Improving Rules and Regulations and Clarifying Each Person's Responsibility.}

Apartment management group and higher school should be consistent in the ideology, objective and action, providing advanced facilities, full equipment, and correct location and establish the long-term mechanism with material culture, institutional culture, behavioral culture and spiritual culture mutually permeating and harmoniously developing, thus developing the spiritual culture of humanistic service, and behavioral edification and cultural education. With the development of our time, we are expected to continuously improve all kinds of rules and regulations and set up efficient mechanism and platform thus forming the legal, reasonable management system with clear responsibility, good operability.

\section{The Specializing of the Management Team and the Professionalizing of the Service Level.}

The first is to pay more attention to the selection and distribution of apartment administrative staff, take the institutional design and occupational requirement into consideration and set up the fair and normative selection procedure, take in the ideologically responsible, high culturally qualified, capable, experienced, and higher level specialized talents with strong sense of service and being able to penetrate into the students' mentality to strengthen the administrative team. We should promote the leaders, professors and instructors to enter the apartment, insist on the idea of "putting people in the principal position" and continuously improve the capability and quality of the administrative team of the apartment culture.

Second, universities need to pay more attention to the training of the administrative staff and hold the preemployment training for the new administrative staff, the backbone project training and the senior seminar of the construction of apartment culture thus implementing the specialized construction of administrative staff comprehensively. They also need to organize the administrative staff to conduct the inspection and training at home and abroad in order to broaden their horizon and enhance their specialization level. What's more, we need to hold occupational skills contest for the administrative staff and exhibit their occupational style, and elevate the scientific level of administrative work thus realizing the transformation of the construction of higher school apartment culture from traditionally spontaneous and experienced method into modern self-conscious and scientific method.

\section{Branding the Cultural Activities and Lasting the Educational Efficiency}

First, universities should implement the student apartment cultural activities closely related to the students' thoughts and their life and also enhance the attraction, infection, pertinence and effectiveness of the ideological and political education and then develop the thoughtful, attractive and qualified brand activities.

The second is to implement the senior leading program, select those who have good qualities, excellent specialized abilities and marvelous skills as the senior, thus facilitating the peer communication, realizing the idea "help people to help themselves and grow up together" and positively constructing the new model of self -educate, self-manage and self-service.

The third is to strengthen the network ideological and political education and take socialist core values as the leading and construct advanced network culture, rely on blog, microblog, QQ chat group, fetion, university wireless interactive education platform and mobile phone newspaper to carry out theme education activities, the interaction online and offline, thus forming the comprehensive force of ideological and political education. 
The fourth is to develop the typical advanced college students, expand the college student apartment culture, excavate their shining point, condense and nurture the college student spirit, build the amiable, respected, reliable and learnable surrounding model, implement the activities such as "the star of apartment" or "the model surrounding you", develop excellent student model and organize "excellent student reports" using the surrounding model to intrigue the comprehensive and healthy growth of the students.

The fifth is to shape the college students' ideals and beliefs to a great degree, adhere to equip them with the latest achievements of the socialist theoretical system and educate them with social core values, give the theme report meeting and theme education activities into full play, actively create the practical carrier for the college students, guide them to internalize the thoughts and take them as the firm political beliefs in the learning practice and then transform the beliefs into the practical action of serving the party and country.

\section{E. Building the Apartment Environment Culture and Shaping the Source Power of Apartment Culture.}

Russian famous educator, Sukhomlinsk, once said, "We are trying to make the walls talk" which emphasized the education of environmental culture. Apartment environment culture is the totality of all the elements involving the environmental design, form, implication and value and also people's evaluations, admiration and anaclitic feeling on these constructions embodied through the apartment building group and the surrounding playground and space. Its concrete embodiment is exactly the carrier of apartment environment culture including every tree and bush, every scene and thing, every apartment and building and every bridge and lake, which all have their own spirituality and give out the inflection, influence and attraction from their own form, state of matter and condition and create the harmonious, comfortable and elegant apartment culture environment thus leaving people in this environment praise it a lot and be enchanted by it deeply, thus influencing people unconsciously and make people comprehend how to conduct oneself and business from it.

\section{CONCLUSION}

In a word, the construction of the college student is a systematic project. The apartment is not only the place where the college students can learn, relax, entertain and communicate among each other, but also the main position for implementing the ideological and political education and fostering the civilized behavior. Therefore, we should exert the function of all school organizations and implement the construction of higher school apartment culture from the perspectives of material culture, spiritual culture, behavioral culture and institutional culture. What's more, we should reform the approaches to constructing higher school student apartment culture, enrich its content and exert the function of apartment culture in the construction of campus culture. The construction of higher school apartment culture should service for the implementation of students' ideological and political education and improve the students' comprehensive qualities completely and develop the qualified successor of socialist.

\section{REFERENCES}

[1] Zhengyu Fan: A Brief Discussion on the Way of Building the Cultural Atmosphere of College Apartments[J], Learning Weekly, 2013(5).

[2] Chen Ji: On the Construction of Apartment Culture in Colleges and Universities[J], Journal of Weinan Normal University(Social Science Edition), 1998(3).

[3] Jianhui Hou: On the Construction of College Students' Apartment Culture[J], Academic Journal of Zhongzhou, 2002(5).

[4] Jianhui Qu: On the Construction of College Students' Apartment Culture[J], Journal of Jiamusi Education Institute, 2013(1).

[5] Peigang Zheng and Bo Qian: On the Construction of College Students' Apartment Culture[J], Journal of Inner Mongolia Normal University(Philosophy and Social Sciences Edition), 2011(5).

[6] Lingling Guo: Challenges and Countermeasures of College Students' Apartment Culture[J], Higher Education Forum, 2006(1). 